\title{
Migration and Mitigation of effect from migration
}

\author{
MGNAS Fernando \\ Senior Lecturer \\ Department of Information Systems Engineering University of Colombo School of Computing \\ Colombo, Sri Lanka
}

\begin{abstract}
It is a fact that most well educated Sri Lankans abandon their land of birth for various reasons. The migration of educated professionals, popularly referred to as the Brain Drain, is not new to Sri Lanka. When well educated people abandon their homes of origin towards greener pastures elsewhere, the nation loses enormous amounts of money spent towards their education. It gets no returns from the vast amounts spent on the highly skilled. Along with such brain drain, the less developed lose not only human resources but are forced to either ignore or abandon efforts for development making the economic divide more and more severe. In Sri Lanka only $10 \%$ of new entrants to schools each year, get selected for university education. On completion most of them migrate for their education elsewhere with improved living conditions and aim towards positions in keeping with their skills. This trend towards migration needs to be arrested and expertise needs to be directed towards national development.

This study investigates mitigating brain drain and attempts to reduce the impact of brain drain on a developing country like Sri Lanka. After extensive research with an experimental survey taking into consideration 10 hypotheses and testing with statistical techniques to analyze the data, the study investigates factors leading to brain drain related mostly to Science, Computing and Engineering related disciplines. It also proposes a sustainable development approach to mitigate the impact of brain-drain on a developing country like Sri Lanka based on a statistical foundation and migrants' views.
\end{abstract}

Keywords: Migrants, Mitigation, Brain Drain, Engineering and Computer Science

\section{Introduction}

Migration has increased over the past years among the academics and professional communities in Sri Lanka for several reasons (Dodani \& LaPorte, 2005; De Silva, et al., 2014). They include: (i) academics after their postgraduate studies (ii) graduates with high academic qualifications anxious to pursue postgraduate studies in a developed country (iii) professionals and academics in search of better living conditions (Dodani \& LaPorte,2005,Gunawardena \& Nawaratne, 2017 ; Pingama, 2017; Srivastava, 2018) .Brain drain is defined as the migration of professionals in search of better standards of living such as quality of life, higher salaries, access to advanced technology and advanced research facilities, and more stable political conditions in different places worldwide( De Silva, et al., 2014). According to (P. Stephan et.,2019; Stephan, Scellato, \& Franzoni, 2015), in USA, more than four out of ten Ph.D. recipients in Science, Computing and Engineering are foreign born. More than six out of ten post-doctoral researches working in the United States were born outside the country and many of them received their PhD outside the country.

Brain Drain is not limited to Sri Lanka alone. Highly educated, skilled and professionals from developing countries migrate permanently with their families to developed regions such as Europe, USA, UK, Australia, New Zealand etc. (Dodani \& LaPorte, 2005). Nevertheless, migration of professionals is a long-recognized problem in Sri Lanka (Gunawardena \& Nawaratne, 2017). It is not clear why a study related to brain drain 
has not been investigated in depth. There are no clear evidences regarding measures to mitigate the problem of "Brain Drain" in a developing country like Sri Lanka (Gunawardena \& Nawaratne, 2017) . Accordingly, this study is an attempt towards fact finding and perhaps, efforts towards mitigating the problem in Sri Lanka.

Nearly $79 \%$ of the annual student population admitted to grade 1-primary education in Sri Lanka sits for the university entrance examination - also called G.C.E (A/L) examination). It has been found that only $51 \%$ of these students are eligible for university admissions. Among the eligible students only $64 \%$ are selected as university candidates for national universities (Education, 2016; UGC, Univeristy Grants Commision, 2016) . In short, only $10 \%$ students get selected to national universities from among those admitted to grade 1 each year. Out of this small number, $12 \%$ and $19 \%$ get selected to the national university system from those sitting the university entrance examination and are eligible for university admission (Education, 2016). According to the above statistics, there is a high filtering mechanism for university admissions which only accepts only those with the highest performances as candidates for state universities. In addition to this intake, a considerable number of students get enrolled for external and internal degrees through national universities and private universities respectively. (UGC, Univeristy Grants Commision, 2016)

The government of Sri Lanka spends $1.89 \%$ from the Gross Domestic Product (GDP) for education and $0.47 \%$ is set apart for higher education. Of this amount $0.41 \%$ is spent for the university education (UGC, Univeristy Grants Commision, 2016) . Education is a major criterion to measure the development of a country and many Sri Lankan families give top priority for their children's education. This priority is a matter of concern towards the importance attached to the problem of graduate employability in the country (Ariyawansa, 2008) . Parental interest and external tuition classes help students to gain admission to the universities, (Ariyawansa, 2008) and parents spend more money for the external tuition classes (Hemachandra , 1985) . Meanwhile, Australia's public investment in tertiary education is among the bottom four of the world's advanced economies - 30th out of 34 nations at $0.7 \%$ of GDP, or about $40 \%$ below the Organization for Economic Co-operation and Development (OECD) average of 1.1\% [10](Maslen, 2017). Even the USA has a higher level of public investment in tertiary education, at $0.9 \%$ of GDP, almost $25 \%$ higher than Australia (Maslen, 2017). The above statistics reveal that the GDP allocation in Sri Lanka for higher education is 57\% level below the OCED average. Further, it is revealed that many Sri Lankan youth consider migration or international schooling as an opportunity to enhance employment prospects(Pingama, 2017;Souza, 2017;Srivastava, 2018) . However, Sri Lanka's tertiary-level student population is quite mobile in part because higher education in Sri Lanka has insufficient capacity to address student demand, especially at the undergraduate level and higher level.

\subsection{Research problem}

In the present context, approximately less than $10 \%$ of Sri Lankan students have a chance to graduate from the Sri Lankan national universities after several filtering mechanisms. Sri Lankan students have enjoyed a system of free education up to university education. In addition, a majority of low-income students receive financial assistance as well as free accommodation. The government of Sri Lanka bears such heavy expenses with the monies collected from tax payers Annually, the national university intake for the medical stream is 1480 students $(4.75 \%)$, whereas for Computer Science, it is 450 students (1.44\%). IT related courses take in 1530 students (4.91\%), and for Engineering, it is 1938 students (6.22\%) (Hemachandra , 1985) . From among this student community, very few students (less than $2 \%$ to 5\%) get a higher class for a degree (first class and second upper (upper division)) for their degree program. Based on the student's academic performance Grade Point Average (GPA) is calculated. There are five categories for the GPA and are as follows: (i)First Class (ii) Second Class (Upper Division) (iii) Second Class (Lower Division) and (iv) General Pass and (v) Fail (Srivastava, 2018;UCSC), 2019). On graduation, a majority of the high academic performances prefers to migrate to developed countries for their post graduate studies, employment etc. A majority of migrants consider settlement abroad.

Economic development and innovative products and services in any country are mostly initiated by skilled educated professionals from the appropriate domains. If such highly skilled professionals migrate, the efforts 
of the country towards educating such people become a waste of resources as the country is unable to obtain the expected outcome. Especially, Science, Computing and Engineering professionals are major resources towards development with their creative and innovative products and services. The government of Sri Lanka spends heavily towards resources. Migration with such a small percentage of highly educated professionals is a big issue to economic stability and sustenance. Therefore, it is timely and important to investigate the factors leading to migration and preventive measures to mitigate migration of professionals towards receiving support from the professionally skilled for development of the home country.

\subsection{Objective of the Study}

The objectives of the study are as follows: To narrow down the prominent factors affecting brain-drain in developing countries, To investigate economic effects of brain drain on a developing country like Sri Lanka, To list down the factors leading towards brain drain as related to Science, Computing and, Engineering disciplines and To investigate sustainable development goals to mitigate the impact of brain-drain in a developing country like Sri Lanka

\subsection{Literature review and theoretical foundation}

Educated skill migration is a severe problem for underdeveloped and developing countries. Educated professionals are the privileged people of the country and the nation spends more resources to create such professionals compared to the other citizens (NSF, 2018). Highly educated skilled people can be globally mobile and many high-income earning avenues are available to makes their knowledge all around the world. They are skilled in knowledge related to advanced development of the country, for Research and Development activities and to provide creative and innovative goods and services to the country. They have high potential to advice key activities from their domain knowledge and advise others. In addition, they are the people to provide for a prosperous country. However, due to brain-drain, the underdeveloped and developing countries face very serious impact on economy, health, innovation, etc. Brain-drain is a drawback to the overall growth and development of the country because any country ends up with a shortage of experts and professionals in key areas especially the Computing, Science and Engineering sectors compromises the quality of the service provided as the ratio between the service provider and the people needing the service is unbalanced. It becomes a two-sided issue where the major cause of the brain drain is poor conditions of services and other factors of the country. Brain drain affects the development of any country. Brain Drain may occur due to the higher contribution of push factors than the contribution of pull factors in a country (Dodani \& LaPorte, 2005).

There are several international migration theories and each of the theories tries to explain migration and development nexus ( Tan \& Marshall, 2017; Kadiri, 2015). This study integrates two international migration theories and one approach (Stephen \& Miller, 2019). It makes use of the Neoclassical migration theory, the New Economics of Labor Migration (NELM) theory, and Brain drain approach. The neoclassical migration theory suggests (Kadiri, 2015) that certain factors such as differences in wages and job opportunities are responsible for the movement of migrants. The NELM suggests that migration is something that is never an individual decision, instead, it is often a collective decision which involves a combination of a group of people, individual families or even communities (Kadiri, 2015). According to the theory (Stanojoska \& Petrevski, 2012), push and pull factors influence the direction of migration (Williams \& Wilkins, 2012) . In the Sri Lankan context and based on the theoretical foundation, the following facts were identified as push and pull factors for migration.

3.1 Push factors: The push factors (encourage people to leave where they are) are negative factors of the home country that form the motivation for skilled educated people migrating from underdeveloped or developing countries. The major push factors are: (i) Unemployment, Discrimination in recruitments and promotions (ii) Lack of research facilities, doctorial, and postgraduate education facilities, including support staff; meagerness of research funds, lack of professional apparatus and tools, (iii) Deteriorating excellence of educational system, (iv) Economic underdevelopment, (v)Social unrest, Political instability, conflicts and wars (vi)Lack of freedom and autonomy, and (vi)Poor working conditions. 
3.2 Pull Factors: Pull factors (encourage people to go to a certain place) are the positive characteristics of the developed country from which the migrant would like to obtain benefits. Such pull factors are: (i) greater income and higher wages (ii) Sophisticated standard of living conditions (iii)superior economic outlook, (iv) the prestige of foreign training, (v)relatively stable political environment, (vi)a modernized educational system to allow for superior training including research and development, doctorial and postgraduate studies (vii) intellectual freedom, (vi)Extensive resources for research, unconventional and advanced technology, modern facilities of laboratory equipment; availability of experienced support workforce and (viii) rich cultures. In addition to the above-mentioned pull factors, some factors may be included to the above list. Such factors can be specific to countries or even to individuals.

Brain drain allows developed countries to devolve further with the use of educated skilled migrants while the skilled migrant's donor countries become poorer in all areas. It will automatically create a global digital divide too. Form childhood, educationally skilled students migrate from rural areas to privileged schools in the city. Among the more educational skilled students, a majority migrates to the capital of the country for tertiary and university education. Completing university education, the highly educated and skilled professionals migrate to developed countries too.

First and foremost, brain drain causes developing countries to lose the ability to progress. Talented people are born, raised, and educated in their country, and when it comes for time to work and give back what they were provided, they leave and seek employment elsewhere. The top three main reasons why people choose to leave their country are: career prospects, social injustice and compensation, with career prospects being the highest percentage at $66 \%$. The country loses people who can help improve the economy and, by extension, the country itself. Highly skilled people are valuable factors in the world economy (Williams \& Wilkins, 2012).

Higher education is one of the principal conduits of permanent migration (Dodani \& LaPorte, 2005) . Most of the science, computing and engineering related professionals acquire specialized and postgraduate professional qualifications in the host country. It has been estimated that foreign scientists from developing countries who are involved in $R \& D$ produce 4.5 more publications and 10 times more patent than the counterpart in the home countries (De Silva, et al., 2014). All the fields including science and technology require following conditions for more R\&D innovations: stable political decisions and policies, funding, infrastructure including modern computer facilities, technical support, IT connectivity and a scientific community (De Silva, et al., 2014) . The above facts are adequately unavailable in developing countries due to various reasons. The value and effectiveness $R \& D$ of individuals depends on their connection to the people, institutions and organizations that enable knowledge creation, and together constitute a propitious environment.

According to the literature review, the following are the main drivers towards brain-drain: (i) better standard of living and quality of life (ii)Limited employment opportunities to come back as against the salaries in the migrated country (iii) Access to advanced technology and to the research culture (iv) more stable political conditions in the developed countries (v) implementation of stable government policies rather than implementation of politicians ad-hoc decisions (vi) disciplinary behavior of the people(vii)lack of research funding and facilities, lack of opportunities for research, postgraduate and doctoral studies, poor facilities and limited career structures(Dodani \& LaPorte, 2005) (viii)Getting married to a host country's citizen to get the citizenship.

The above facts reveal that it is a difficult task to stop skilled migration from the developing and underdeveloped countries in the present context. But there are avenues to get various contributions to the home country from the migrated. Further, when obtaining contribution to the home country from migrants their rights cannot be violated, and their freedom also needs to be protected. It must also be remembered that the mother country provides for education bearing heavy expenses towards the creation of such professionals. Therefore, considering the above contradictory facts a win-win situation is needed for sustainable development in any country. Further, the majority of skilled professional migrants are not 
willing to come back to the home country due to the existing privileges in the host country - privileges that are denied in the mother country. Previous studies on the topic reveal that lack of mechanism drives towards mitigation of the educated skilled migrations or to get their support towards sustainable development of the home country. Hence, as a country it has to be explored as to how educated skilled migration can be lessened and to get their support towards development of the home country. It is no exaggeration that contributions from the educated skilled professionals are highly beneficial to the development of the any country. It is imperative that expertise be harnessed. Further, according to Sri Lankan culture, there is a close relationship with family members and relatives. In keeping with these commitments, migrants often make frequent visits to their home country.

\subsection{Methodology}

The nature of this study was exploratory and adopted a judgmental approach. This meant ascertaining causes, the extent and solutions to brain drain in Sri Lanka. The research design used qualitative and quantitative measures using judgmental and purposeful techniques for gather data through random sampling. The study was carried out in two phases as follows:

Qualitative and quantitative design was used to collect pure and inner views of the respondents in unstructured and structured manners. For the sample age, years 25 to 40 were selected.

This study was carried out in two phases as follows:

4.1 Phase I: secondary data was collected from different sources available in scholarly articles, related official websites, selected publications of University Grants Commission (UGC) of Sri Lanka and other responsible data sources as example data related to the doctorate recipients of Sri Lankan citizenship with temporary visas intending to stay in the United States after receiving the Doctorates from 2010-2015 from the USA NSF database(NSF, 2018).

4.2 Phase II: Using records of national universities and personal contacts of peers of migrants, the study was able to find more than hundreds of e-mail addresses of participants studying/studied postgraduate degrees and $\mathrm{PhD}$ in foreign countries and are still in a foreign country after graduation from the Sri Lankan national universities. This study designed a questionnaire to fill the gaps in the literature review as way of finding a solution to the research problem. The designed questionnaire created a URL for the survey, then got responses by emailing the link through the known email client. Feedback from migrants was requested via e-mails. Migrants were expected to email their responses, and their feedback was automatically updated to the designed database. Out of more than 100 participants, 59 responses were collected from the migrants.

The data of the questionnaire included their current places of living, how long they have been in the country, status about permanent settlement overseas, reasons for living outside Sri Lanka, investigation into the negative effects due to the brain drain from their view point, the precautions and their proposals to mitigate brain drain from Sri Lanka, etc. The sample was selected according to random judgment sampling techniques (Castles, De Haas, \& Miller, 2014);Williams \& Wilkins, 2012). In addition, the appropriate qualitative facts were collected through social media conversations like Skype and Messenger services to fill gaps in the study.

The data were analyzed based on both descriptive and inferential statistics using SPSS version 22.0 and Minitab Version 18. Frequencies were made to run for the generation of descriptive statistics. Considering the important variable in the survey, basic statistics (where applicable) are presented in Table and/or chart form. Further, hypothesis testing was used for the analysis. Mainly Kruskal-Wallis test was used to investigate the major reasons for migrating and proposal to mitigate skill migration from the view point of migrants. Further analysis included the major reasons for migrations and possibilities to get the support from the migrants to develop the host country.

\subsection{Hypothesis Testing}


In addition to the descriptive statistical analysis, the analysis was continued based on the following list of 10 hypotheses as shown in Table 1.0

\section{Table 1: List of Hypothesis testing}

\begin{tabular}{|c|c|}
\hline \multirow[t]{2}{*}{ Hypothesis I } & $\begin{array}{l}\mathrm{H}_{0} \text { : Educated skilled professionals' migration can be mitigated by providing wider and better job } \\
\text { opportunities. }\end{array}$ \\
\hline & $\begin{array}{l}\mathrm{H}_{1} \text { : Educated skilled professionals' migration cannot be mitigated by providing wider and better job } \\
\text { opportunities }\end{array}$ \\
\hline \multirow[t]{2}{*}{ Hypothesis 2} & $\begin{array}{l}\mathrm{H}_{0} \text { : Educated skilled professionals' migration can be mitigated by providing smart academic and } \\
\text { research opportunities }\end{array}$ \\
\hline & $\begin{array}{l}\mathrm{H}_{1} \text { : Educated skilled professionals' migration cannot be mitigated by providing smart academic and } \\
\text { research opportunities }\end{array}$ \\
\hline \multirow[t]{2}{*}{ Hypothesis 3} & $\begin{array}{l}\mathrm{H}_{0} \text { : Educated skilled professionals' migration can be mitigated by providing and facilitating a friendly } \\
\text { cooperative and healthy work environment }\end{array}$ \\
\hline & $\begin{array}{l}\mathrm{H}_{1} \text { : Educated skilled professionals' migration cannot be mitigated by providing and facilitating a } \\
\text { friendly cooperative and healthy work environment }\end{array}$ \\
\hline \multirow[t]{2}{*}{ Hypothesis 4} & $\begin{array}{l}\mathrm{H}_{0} \text { : Educated skilled professionals' migration can be mitigated by facilitating less political influence } \\
\text { and corruptions in the work environment }\end{array}$ \\
\hline & $\begin{array}{l}\mathrm{H}_{1} \text { : Educated skilled professionals' migration cannot be mitigated by facilitating less political } \\
\text { influence and corruptions in the work environment }\end{array}$ \\
\hline \multirow[t]{2}{*}{ Hypothesis 5} & $\mathrm{H}_{0}$ : Educated skilled professionals' migration can be mitigated by facilitating freedom of occupation \\
\hline & $\begin{array}{l}\mathrm{H}_{1} \text { : Educated skilled professionals' migration cannot be mitigated by facilitating freedom of } \\
\text { occupation }\end{array}$ \\
\hline \multirow[t]{2}{*}{ Hypothesis 6} & $\begin{array}{l}\mathrm{H}_{0} \text { : Educated skilled professionals' migration can be mitigated by facilitating the possibility of } \\
\text { professional growth, financial security and congenial work environment in the work environment. }\end{array}$ \\
\hline & $\begin{array}{l}\mathrm{H}_{1} \text { : Educated skilled professionals' migration cannot be mitigated by facilitating the possibility of } \\
\text { professional growth, financial security and congenial work environment in the work environment }\end{array}$ \\
\hline \multirow[t]{2}{*}{ Hypothesis 7} & $\begin{array}{l}\mathrm{H}_{0} \text { : Educated skilled professionals' migration can be mitigated by facilitating lenient immigration } \\
\text { policies with the work environment }\end{array}$ \\
\hline & $\begin{array}{l}\mathrm{H}_{1} \text { : Educated skilled professionals' migration cannot be mitigated by facilitating lenient immigration } \\
\text { policies with the work environment. }\end{array}$ \\
\hline \multirow[t]{2}{*}{ Hypothesis 8} & $\begin{array}{l}\mathrm{H}_{0} \text { : Educated skilled professionals' migration can be mitigated by facilitating pursuit for higher } \\
\text { education and economic improvement environment }\end{array}$ \\
\hline & $\begin{array}{l}\mathrm{H}_{1} \text { : Educated skilled professionals' migration cannot be mitigated by facilitating pursuit for higher } \\
\text { education and economic improvement environment }\end{array}$ \\
\hline \multirow[t]{2}{*}{ Hypothesis 9} & $\mathrm{H}_{0}$ : Educated skilled professionals' migration can be mitigated by facilitating political freedom \\
\hline & $\mathrm{H}_{1}$ : Educated skilled professionals' migration cannot be mitigated by facilitating political freedom \\
\hline Hypothesis 10 & $\mathrm{H}_{0}$ : Educated skilled professionals' migration can be mitigated by facilitating high level living \\
\hline
\end{tabular}


$\mathrm{H}_{1}$ : Educated skilled professionals' migration cannot be mitigated by facilitating high level living conditions

\subsection{Results}

The study reveals that, 39\% migrants are permanently settled in respective countries.40.7\% of migrants are not yet decided about coming back to Sri Lanka or to settle down in respective countries. Further, 20.3\% of migrants say they would like to come back to Sri Lanka after a certain period or after their assignment/task is over.

The following Figure 1.0 shows the percentages of Computing/Engineering and Science educated professionals migrated to different countries.

Figure 1.0: Percentage of educated professionals migrated.

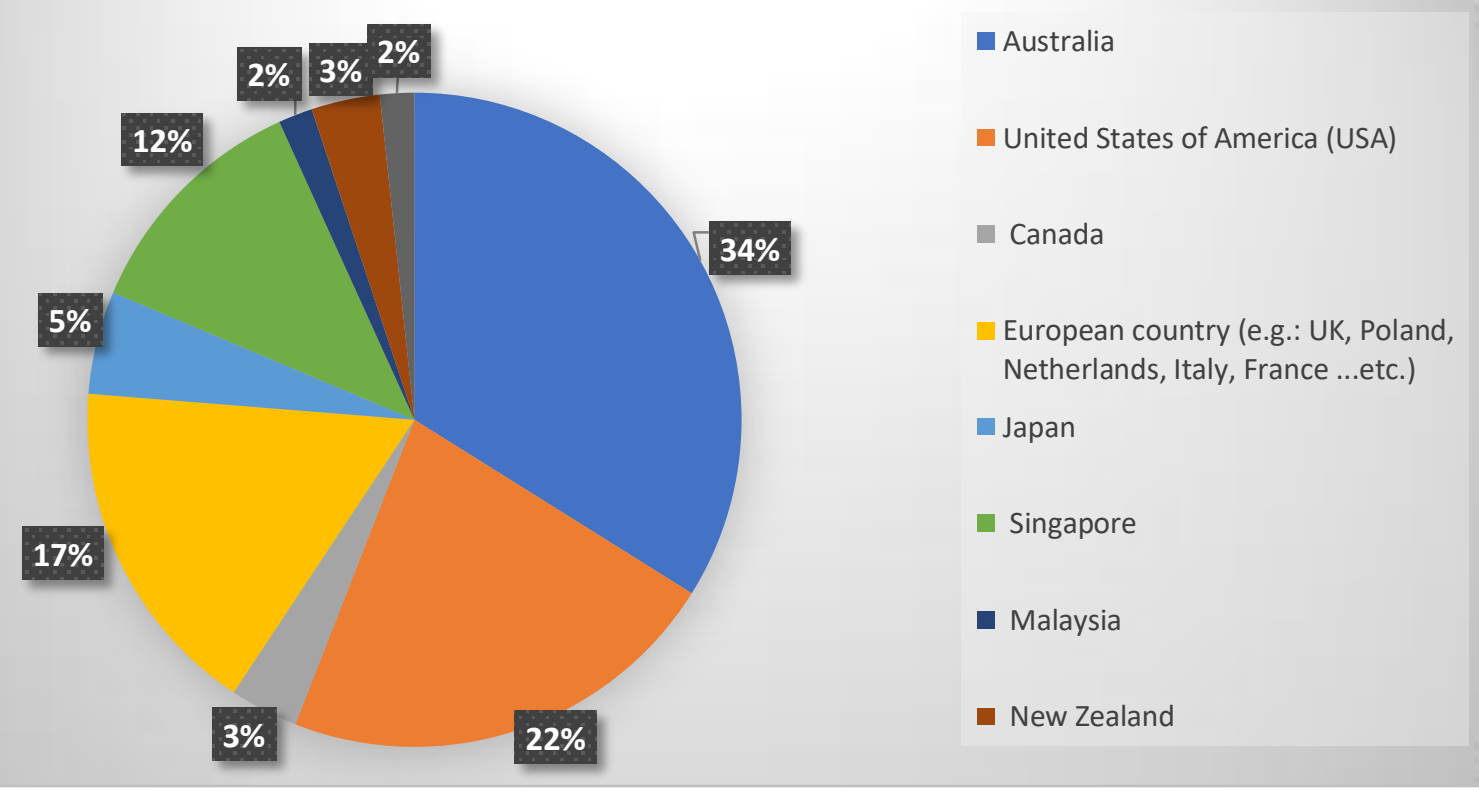

As shown in Figure 1.0, most professionals have migrated to Australia, USA and European countries. Further analysis reveals that the major reasons for the not returning back to the home country are as follows: (a) Comfortable living styles/conditions more well-matched than in Sri Lanka with well-established safe and fast public transport systems, reliable well facilitated health and education systems (b)Lack of improvement in the county due to present and past governments activities, (c) Corruption activities in the government - lack of policies and poor implementation of policies, (d) No proper recognition for skills (e) Lack of career opportunities and lack of research and development facilities (lack of advanced technological development including infrastructure, funding, due to lack of potential supervising professionals(f) research and development and infrastructure, especially at $\mathrm{PhD}$ level, qualification or research work not relevant in the country other than the academia),(g) not utilizing tax payers' money for development activities of the country. More analysis proved that $88.1 \%$ of highly academically qualified and intelligent people migrate from the country. This factor more or less proves that Sri Lanka is witnessing brain drain. Moreover, the analysis of the study shows $96.6 \%$ of professional migrants believe that brain drain will negatively impact on the economics of the development of the country. Going further, the study reveals that a majority of professional migrants are willing to be involved in the development of Sri Lanka (i) as an entrepreneur providing new ideas (ii) an investor related with innovative projects if it is a secure investment (iii) a provider of technical knowledge as a researcher and a consultant (iv) a guide willing to assist with 
improving research culture in Sri Lanka and (v) a provider of expert knowledge and advice to the development activities of Sri Lanka according to their simplicity using foreign exposure.

The following Figure 2.0 shows Doctorate recipients with Sri Lankan citizenship and temporary visas intending to stay in the United States after receipt of Doctorate: 2010-15(NSF,2018).

Figure 2.0 Doctorate recipients of Sri Lankan citizenship with temporary visas intending to stay in the United States after doctorate receipt: 2010-2015(NSF, 2018)

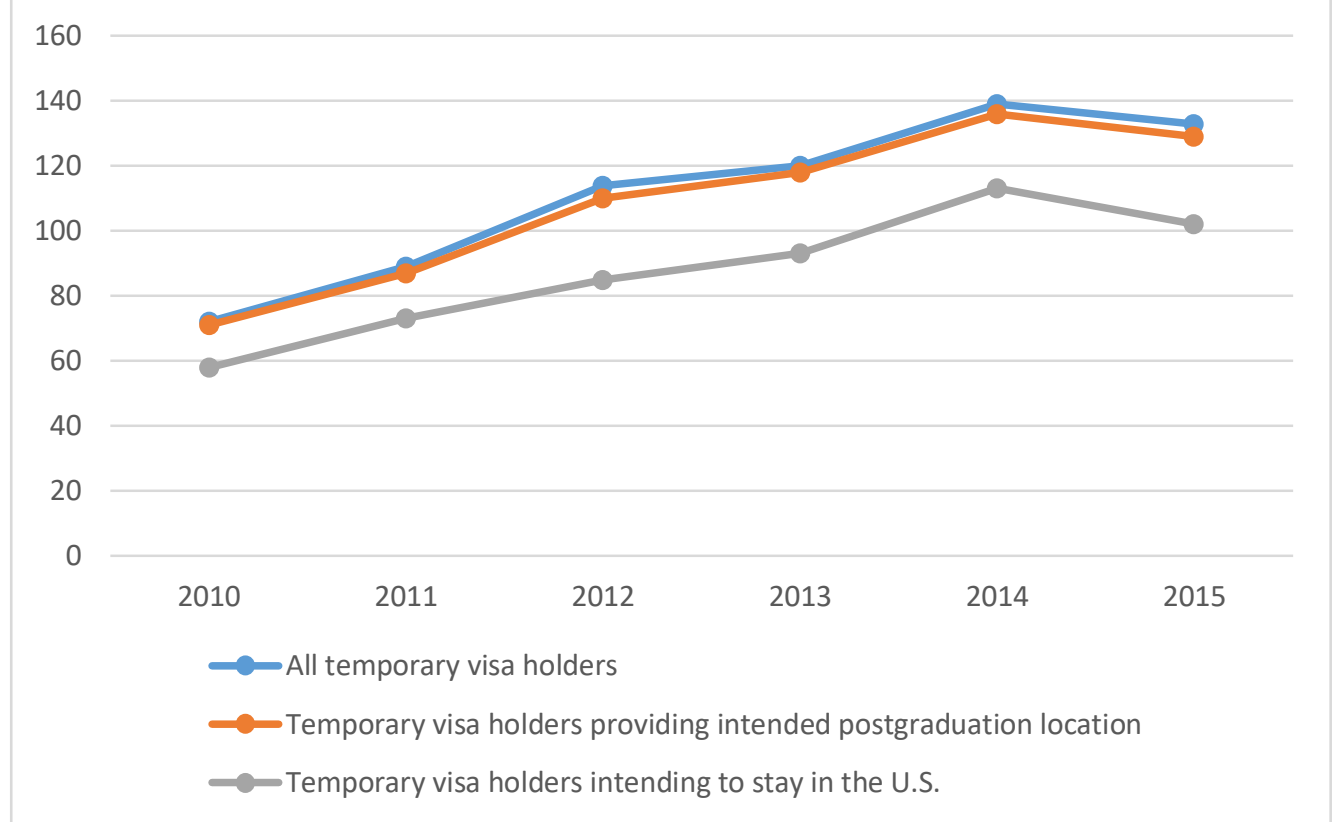

According to the above graph, it is very clear that a majority of temporary visa holders who are engaged in Doctoral studies in USA are willing to settle down in USA after receiving their Doctorates. They are the hierarchy of the educated Sri Lankan educated category and they have faced high-level filtering processes during their education. This category could easily be an effective workforce and resources for the development of Sri Lanka's economy. This study, Mainly Kruskal-Wallis test was used to investigate the major reasons for migration.

The outcome from the 10 hypotheses testing reflects the view points of the skilled migrants to mitigate skilled migration while leading to a proposal towards a solution.

Based on the outcome of the above 10 hypothesis, the summarized results are represented as follows:

\subsection{The Outcome of Hypothesis 1}

Table 1.2 shows the outcome of hypothesis 1 based on the Kruskal-Wallis test

Table 1.2: The outcome of Hypothesis 1

\begin{tabular}{|c|c|c|c|c|}
\hline Country & $\mathrm{N}$ & Median & Mean Rank & Z-Value \\
\hline Australia & 19 & 1 & 28.5 & -0.16 \\
\hline $\begin{array}{l}\text { United States of America } \\
\text { (USA) }\end{array}$ & 13 & 1 & 29.2 & 0.05 \\
\hline Canada & 2 & 1 & 27 & -0.17 \\
\hline $\begin{array}{l}\text { European country (e.g.: UK, } \\
\text { Poland, Netherlands, Italy, } \\
\text { France ...etc.) }\end{array}$ & 10 & 1 & 29.9 & 0.18 \\
\hline Japan & 3 & 1 & 27 & -0.21 \\
\hline China & 7 & 1 & 31.1 & 0.35 \\
\hline
\end{tabular}




\begin{tabular}{|c|c|c|c|c|}
\hline Korea & 2 & 1 & 27 & -0.17 \\
\hline $\begin{array}{l}\text { Singapore and other } \\
\text { countries }\end{array}$ & 1 & 1 & 27 & -0.12 \\
\hline Overall & 57 & & 29 & \\
\hline Test & & & & \\
\hline Null hypothesis & $\mathrm{H}_{0}$ : All medians are equal & & & \\
\hline Alternative hypothesis & $\begin{array}{l}\mathrm{H}_{1} \text { : At least one median is } \\
\text { different }\end{array}$ & & & \\
\hline Method & $\mathrm{DF}$ & H-Value & P-Value & \\
\hline Not adjusted for ties & 7 & 0.27 & 1 & \\
\hline Adjusted for ties & 7 & 1.38 & 0.986 & \\
\hline
\end{tabular}

The $\mathrm{P}$ value of the Kruskal-Wallis test on total rank is 0.986 (adjusted for ties). As the $\mathrm{P}$ value is greater than the significant level $(\alpha=0.05), \mathrm{H}_{0}$ cannot be rejected. It can be concluded that

"Educated skilled professional migration can be mitigated by providing wider and better job opportunities" Outcome from Hypotheses 2-10 are shown in Tables 3.0 to Table 11.0 and are as follows:

Similarly, Kruskal-Wallis test was applied to the remaining hypotheses of the study as described in the methodology section. A summary of the Hypotheses testing results are presented in Tables 3.0 to 11.0

\subsection{The Outcome of Hypothesis 2}

Table 3: The Outcome of Hypothesis 2

\begin{tabular}{|l|r|r|r|}
\hline Null hypothesis & \multicolumn{3}{|c|}{$\mathrm{H}_{0}$ : All medians are equal } \\
\hline Alternative hypothesis & \multicolumn{2}{|c|}{$\mathrm{H}_{1}$ : At least one median is different } \\
\hline Method & DF & H-Value & P-Value \\
\hline Not adjusted for ties & 7 & 0.37 & 1.000 \\
\hline Adjusted for ties & 7 & 7.14 & 0.414 \\
& & & \\
\hline
\end{tabular}

The $\mathrm{P}$ value of the Kruskal-Wallis test on total rank is 0.414 (adjusted for ties). As the $\mathrm{P}$ value is greater than the significant level $(\alpha=0.05), \mathrm{H}_{0}$ cannot be rejected. It can be concluded that "educated skilled professional migration can be mitigated by providing smart academic and research opportunities".

\subsection{The Outcome of Hypothesis 3}

Table 4: The outcome of Hypothesis 3

\begin{tabular}{|l|r|r|r|}
\hline Null hypothesis & \multicolumn{3}{|c|}{$\mathrm{H}_{0}$ : All medians are equal } \\
\hline Alternative hypothesis & \multicolumn{2}{|c|}{$\mathrm{H}_{1}$ : At least one median is different } \\
\hline Method & DF & H-Value & P-Value \\
\hline Not adjusted for ties & 7 & 3.74 & 0.809 \\
\hline Adjusted for ties & 7 & 8.62 & 0.281 \\
\hline & & & \\
\hline
\end{tabular}


The $\mathrm{P}$ value of the Kruskal-Wallis test on total rank is 0.281 (adjusted for ties). As the $\mathrm{P}$ value is greater than the significant level $(\alpha=0.05), \mathrm{H}_{0}$ cannot be rejected. It can be concluded that "educated skilled professional migration can be mitigated by providing and facilitating a friendly, cooperative and healthy work environment".

\subsection{The Outcome of Hypothesis 4}

Table 5: The Outcome of Hypothesis 4

\begin{tabular}{|c|c|c|c|}
\hline Null hypothesis & $\mathrm{H}_{0}$ : All medians are equal & & \\
\hline Alternative hypothesis & $\mathrm{H}_{1}$ : At least one median is different & & \\
\hline Method & DF & H-Value & P-Value \\
\hline Not adjusted for ties & 8 & 1.42 & 0.994 \\
\hline Adjusted for ties & 8 & 5.09 & 0.748 \\
\hline
\end{tabular}

The $\mathrm{P}$ value of the Kruskal-Wallis test on total rank is 0.748 (adjusted for ties). As the $\mathrm{P}$ value is greater than the significant level $(\alpha=0.05), \mathrm{H}_{0}$ cannot be rejected. It can be concluded that "educated skilled professional migration can be mitigated by facilitating less political influence and corruptions with work environment".

\subsection{The Outcome of Hypothesis 5}

Table 6: The Outcome of Hypothesis 5

\begin{tabular}{|l|r|r|r|}
\hline Null hypothesis & \multicolumn{3}{|c|}{$\mathrm{H}_{0}$ : All medians are equal } \\
\hline Alternative hypothesis & \multicolumn{2}{|c|}{$\mathrm{H}_{1}$ : At least one median is different } \\
\hline Method & DF & H-Value & P-Value \\
\hline Not adjusted for ties & 7 & 5.71 & 0.574 \\
\hline Adjusted for ties & 7 & 17.66 & 0.014 \\
\hline
\end{tabular}

The $\mathrm{P}$ value of the Kruskal-Wallis test on total rank is 0.014 (adjusted for ties). As the P value is not greater than the significant level $(\alpha=0.05), H_{0}$ can be rejected. It can be concluded that “educated skilled professional migration cannot be mitigated by facilitating freedom of occupation. They are not considered as freedom of occupation as the more significant factor to mitigate the migration.

\subsection{The Outcome of Hypothesis 6}

Table 7: The Outcome of Hypothesis 6

\begin{tabular}{|l|r|r|r|}
\hline Null hypothesis & \multicolumn{3}{|c|}{$\mathrm{H}_{0}$ : All medians are equal } \\
\hline Alternative hypothesis & \multicolumn{2}{|c|}{$\mathrm{H}_{1}$ : At least one median is different } \\
\hline Method & DF & H-Value & P-Value \\
\hline Not adjusted for ties & 8 & 4.15 & 0.843 \\
\hline Adjusted for ties & 8 & 17.56 & 0.025 \\
\hline
\end{tabular}

The $\mathrm{P}$ value of the Kruskal-Wallis test on total rank is 0.025 (adjusted for ties). As the P value is not greater than the significant level $(\alpha=0.05), \mathrm{H}_{0}$ can be rejected. It can be concluded that 
“educated skilled professionals' migration cannot be mitigated by facilitating the possibility of professional growth, financial security and congenial work environment in the work environment".

\subsection{The Outcome of Hypothesis 7}

Table 8: The Outcome of Hypothesis 7

\begin{tabular}{|l|r|r|r|}
\hline Null hypothesis & \multicolumn{3}{|c|}{$\mathrm{H}_{0}$ : All medians are equal } \\
\hline Alternative hypothesis & \multicolumn{2}{|c|}{$\mathrm{H}_{1}$ : At least one median is different } \\
\hline Method & DF & H-Value & P-Value \\
\hline Not adjusted for ties & 7 & 4.93 & 0.669 \\
\hline Adjusted for ties & 7 & 7.53 & 0.376 \\
\hline
\end{tabular}

The $\mathrm{P}$ value of the Kruskal-Wallis test on total rank is 0.376 (adjusted for ties). As the $\mathrm{P}$ value is greater than the significant level $(\alpha=0.05), \mathrm{H}_{0}$ cannot be rejected. It can be concluded that “educated skilled professionals' migration can be mitigated by facilitating lenient immigration policies with the work environment".

\subsection{The Outcome of Hypothesis 8}

Table 9: The Outcome of Hypothesis 8

\begin{tabular}{|l|r|r|r|}
\hline Null hypothesis & \multicolumn{3}{|c|}{$\mathrm{H}_{0}$ : All medians are equal } \\
\hline \multicolumn{2}{|l|}{ Alternative hypothesis } & \multicolumn{2}{|c|}{$\mathrm{H}_{1}$ : At least one median is different } \\
\hline Method & DF & H-Value & P-Value \\
\hline Not adjusted for ties & 8 & 1.25 & 0.996 \\
\hline Adjusted for ties & 8 & 6.51 & 0.591 \\
\hline & & & \\
\hline
\end{tabular}

The $\mathrm{P}$ value of the Kruskal-Wallis test on total rank is 0.591 (adjusted for ties). As the $\mathrm{P}$ value is greater than the significant level $(\alpha=0.05), \mathrm{H}_{0}$ cannot be rejected. It can be concluded that “educated skilled professionals' migration can be mitigated by allowing for a pursuit of higher education and economic improvement".

\subsection{The Outcome of Hypothesis 9}

Table 10: The Outcome of Hypothesis 9

\begin{tabular}{|l|r|r|r|}
\hline Null hypothesis & \multicolumn{3}{|c|}{$\mathrm{H}_{0}$ : All medians are equal } \\
\hline Alternative hypothesis & \multicolumn{2}{|c|}{$\mathrm{H}_{1}$ : At least one median is different } \\
\hline Method & DF & H-Value & P-Value \\
\hline Not adjusted for ties & 7 & 4.45 & 0.727 \\
\hline Adjusted for ties & 7 & 9.51 & 0.218 \\
\hline
\end{tabular}

The $\mathrm{P}$ value of the Kruskal-Wallis test on total rank is 0.218 (adjusted for ties). As the $\mathrm{P}$ value is greater than the significant level $(\alpha=0.05), \mathrm{H}_{0}$ cannot be rejected. It can be concluded that “educated skilled professionals' migration can be mitigated by facilitating political freedom”.

\section{Hypothesis 10}

5.10 The Outcome of Hypothesis 10 


\begin{tabular}{|l|r|r|r|}
\hline Null hypothesis & \multicolumn{3}{|c|}{$\mathrm{H}_{0}$ : All medians are equal } \\
\hline Alternative hypothesis & \multicolumn{2}{|c|}{$\mathrm{H}_{1}$ : At least one median is different } \\
\hline Method & DF & H-Value & P-Value \\
\hline Not adjusted for ties & 8 & 1.27 & 0.952 \\
\hline Adjusted for ties & 8 & 6.41 & 0.541 \\
\hline & & & \\
\hline
\end{tabular}

The $\mathrm{P}$ value of the Kruskal-Wallis test on total rank is 0.541 (adjusted for ties). As the $\mathrm{P}$ value is greater than the significant level $(\alpha=0.05), \mathrm{H}_{0}$ cannot be rejected. It can be concluded that educated skilled professionals' migration can be mitigated by facilitating high level living conditions

\subsection{Discussion and Conclusion}

The results of the analysis show that $39 \%$ of educated skilled migrants are permanently settled in different counties and $40.7 \%$ of migrants are not yet decided to come back to Sri Lanka or settle in respective countries. Further, $20.3 \%$ of migrants say they would like to come back to Sri Lanka after a certain period or at the completion of their assignment/task. Based on the outcomes of the analysis, it reveals that there is a possibility to increase the numbers of returning migrants up to $61 \%$ with the implementation of productive, sustainable strategies and policies.

Outcome from 8 out of 10 hypotheses tested contribute towards concluding that if the relevant authorities pay more attention to enable the following facts, educated skilled professional migration can be mitigated. The facts are: (i) the provision of wider and better job opportunities (ii) the provision of smart academic and research opportunities (iii) facilitating a friendly cooperative and healthy work environment (iv) encouraging less political influence and corruptions with the work environment (v) facilitating lenient immigration policies with the work environment (vi) providing higher education opportunities and economic improvement processes (vii) facilitating political freedom(viii) facilitating high level living conditions.

In addition to the above facts, the analysis reveals that educated skilled migrants are willing to get involved in the following processes to the development of Sri Lanka: (i) as an entrepreneur providing new ideas (ii) as an investor towards related innovative projects if the investment is secure (iii) as a researcher and consultant providing technical knowledge (iv) as a guide towards improving research culture in Sri Lanka and (v) with foreign exposure provide expertise and advice towards simple and practical approaches towards the development activities of Sri Lanka.

The above facts reveal that there is a possibility for acceptable contribution from the educated skilled migrants even if they are not permanently settled in Sri Lanka. In summary, the analysis says, if there is a solid sustainable policy framework and development of economics strategies brain drain can be mitigated. Further, most migrants stated that Sri Lanka is a beautiful country and is a good place for living considering geographical and other factors. If other factors like: higher salaries, education opportunities etc. are fulfilled as compared to the developed counties, migration can be mitigated. It is believed that obtaining services, resources and other types of contributions from migrants could bridge the gap resulting from a lack of educated skills migrants. Giving an ear to the requests of skilled migrants and assuring better prospects in the land of birth can, to some extent, mitigate the migration of skilled educated personnel. Sustainable development goals can be achieved if the relevant authorities use strategic approaches to get the services and resources from the educated skilled migrants as they proposed.

\section{Acknowledgement}

I would like to express my sincere thanks to Ms. Shashikala Ruwanmini for her valuable contribution to preparing the questionnaire and creating the database to collect data from the participants for the survey.

\section{References}


[1] Ariyawansa, R. (2008). Employability of Graduates of Sri Lankan Universities. Sri Lankan Journal of Human Resource Managemen, Vol. 2, No. 1, pp. 91-104.

[2] Castles, S., De Haas, H., \& Miller, M. J. (2014). The Age of Migration. UK: Palgrave Macmillan.

[3] De Silva, L. N., Samarasekara, K., Rodrigo, C., Samarakoon, L., Fernando, S. D., \& Rajapakse, S. (2014). Why do doctors emigrate from Sri Lanka? A survey medical undergraduates and new graduates. BioMed Central, 7(1):918.

[4] Dodani , S., \& LaPorte, R. E. ( 2005). Brain drain from developing countries: how can brain drain be converted into wisdom gain? Journal of the Royal Society of Medicine, Vol. 98, No 3 , pp. 487-491 .

[5] Education, M. o. (2016). School Census, Priliminary Report -2016. Colombo: Statistical Branch, Minsitry of Education .

[6] Gunawardena, C., \& Nawaratne, R. (2017). Brain Drain from Sri Lankan Universities. Sri Lanka Journal of Social Sciences, Vol. 40 , No. 2, pp. 103-118.

[7] Hemachandra, H. L. (1985, july). THE TUITION CLASS, SOCIAL CLASS AND EDUCATIONAL. Retrieved from The Nexus between Socio-Economic Factors ... Economic Review: http://dl.nsf.ac.lk/bitstream/handle/1/14932/ER-11(4-5)-54.pdf?sequence=2

[8] Kadiri, K. (2015). Migration and Brain Drain:A Case Study of African Students in Southern,Sweden. Sweden: Lund University.

[9] Maslen, G. (2017). Higher education spending among world's lowest - OECD. London : Isuusu :474, University World News, the global window on higher education.

[10] NSF,National Science foundation. (2018, 12 22). Survey of Earned Doctorates. (NSF) Retrieved 4 20, 2019, from https://www.nsf.gov/statistics/srvydoctorates/

[11] Pingama, A. (2017). Migration Intentions of Post War Youths in Sri Lanka: A Systematic Review of Literature on Causes of Migration. 13th International Conference on Business Management (ICBM) 2016. (p. 19). Colombo: Unversity of Sri Jayawardenapura.

[12] Souza, J. D. (2017). Education in Sri Lanka. Colombo: Asia Pacific, WENR.

[13] Srivastava, B. (2018). International cooperation to manage high-skill migration: The care of IndiaU.S. relations. American Economic Association. usa.

[14] Stanojoska, A., \& Petrevski, B. (2012). Theory of push and pull factors: a new way of explaining the old. Archibald Reiss Days. Serbia.

[15] Stephan, P., Scellato, G., \& Franzoni, C. (2015). Migrant Scientists and International Networks: Diaspora and Home Country. Seoul: Korean Development Institute.

[16] Stephen, C., \& Miller, J. M. (2019). The Age of Migration: International Population Movements in the Modern World. Journal of Contemporary European Research, Vol 17 No 2.

[17] Tan, A., \& Marshall, S. (2017). Without immigrants, the US economy would be a 'disaster. Washington: ABC News Live.

[18] UGC, (2016). Univeristy Grants Commision. Statistical Hand Book. Colombo : Univeristy Grants Commision, Sri Lanka.

[19] UCSC( 2019). University of Colombo School of Computing, Student Hand Book-2019. Colombo: UCSC

[20] Williams , L., \& Wilkins. (2012). Judgment Sampling: A Health Care. Q Manage Health Care, 21(3), 170-176. 